\title{
DSP based Voltage Source Inverter for an application of Induction Motor control
}

\author{
Venu Gopal Mangali ${ }^{1}$, Shravan Kumar $P^{1}$, Vinay Kumar Awaar ${ }^{2}$, and Praveen Jugge ${ }^{3}$ \\ ${ }^{1}$ UG Student, ${ }^{2}$ Associate Professor, ${ }^{3}$ Professor \\ Department of Electrical and Electronics Engineering, \\ Gokaraju Rangaraju Institute of Engineering and Technology, Hyderabad, India.
}

\begin{abstract}
The paper presents a Single-phase inverter configuration dependent on IGBTs utilizing a Digital Signal Processor by the SPWM method. The equipment configuration is actualized utilizing IGBT Inverter Module. The equipment results are examined in the paper. The IGBT, which requires $15 \mathrm{v}$ of activating pulse to their individual gates, is taken care of through the isolation circuit. The circuit is intended to enhance the pulse from the DSP controller, up to the necessary abundancy, and goes about as an isolation circuit. The inverter input is given through the DC rectifier circuit with consistent voltage, and the output is Controllable $\mathrm{AC}$ with variable voltage and frequency.
\end{abstract}

\section{INTRODUCTION}

The transformation of Direct current into an Alternating current is done by a procedure called Inversion, and a gadget is called an inverter. Inverters are predominantly actualized where DC power needs to take care of into AC loads. Inverters have a significant impact on power electronics innovation and drives, for example, AC motor speed control. PWM strategy is most ordinarily utilized in Inverter Innovation. The PWM based inverters have more predominance than different kinds of inverters. PWM is produced from various sorts of controllers, here DSP Launchpad is utilized. The qualities of the PWM wave establish that the output voltage contains harmonics. Resonant filters are utilized at the inverter output terminals to alter the output voltage and current waveforms direct sine wave shape and decrease the nearness of harmonics on the load.

\section{INVERTER}

In general, there are two kinds of inverters, voltage source inverters (VSI) and current source inverters (CSI). At the point when an inverter has a consistent DC voltage source at its entering terminal, it is known as a VSI. At the point when the inverter DC source has a firm DC current source, the inverter is known as a CSI.

\subsection{Half-Bridge Inverter}

On account of RL load, the opposite load current moves through the diodes. They offer a substitute way to an inductive current, which proceeds so stream during the Turn OFF condition.

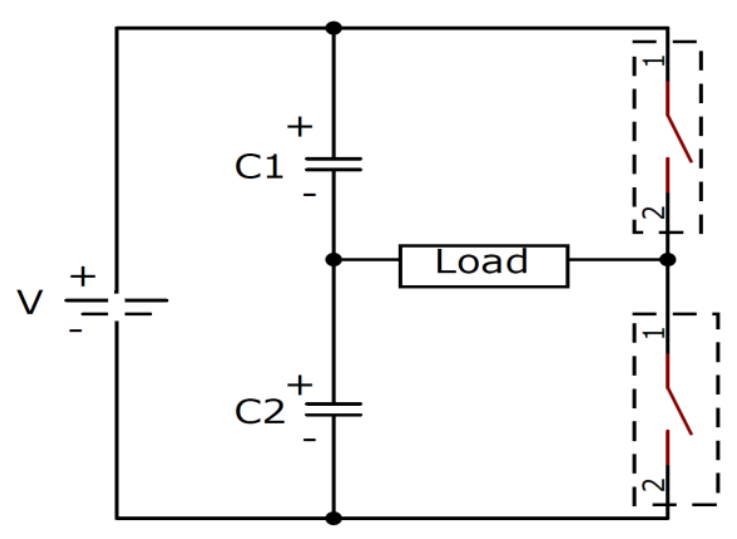

Fig.1. Half-bridge inverter

\subsection{Full-Bridge Inverter}

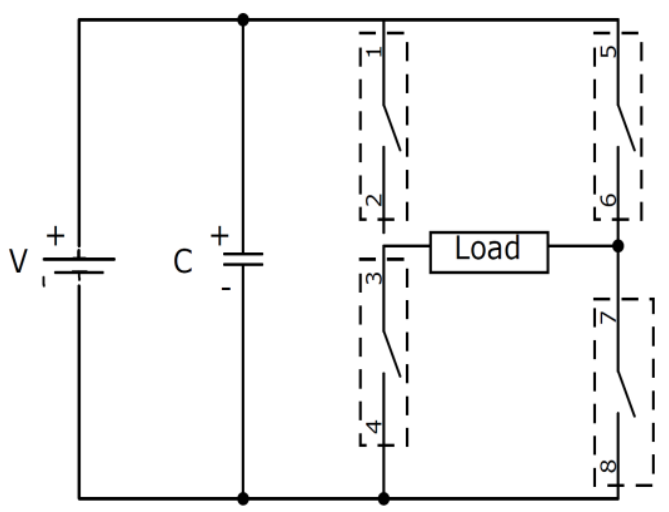

Fig.2.Full- Bridge Inverter 


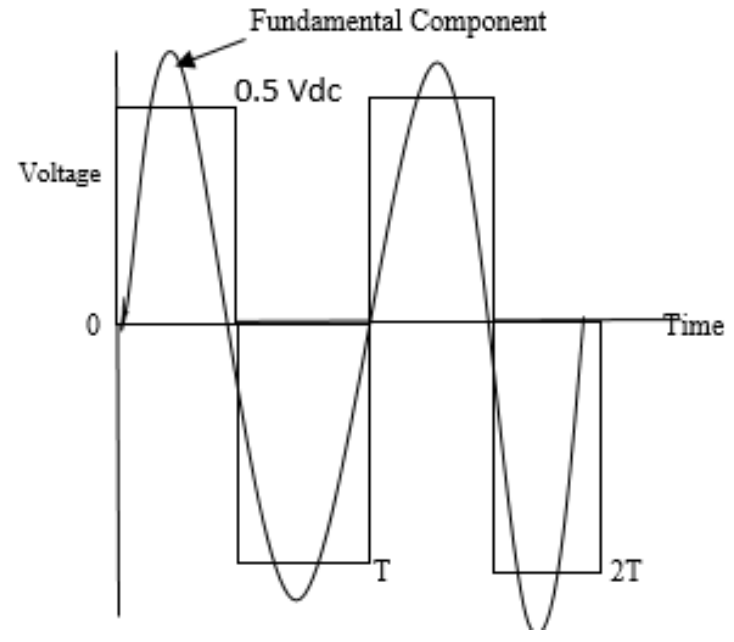

Fig.3. The voltage waveform of a Half-Bridge inverter

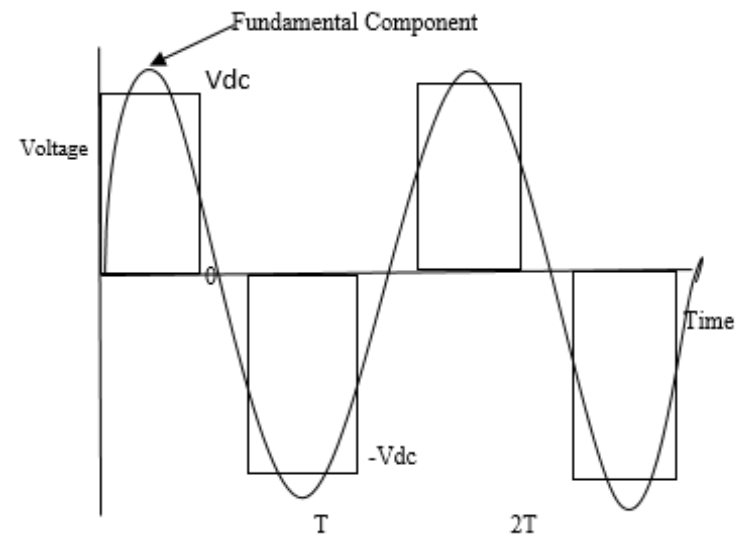

Fig.4.The voltage waveform of a Full-Bridge inverter

The load voltage representations shown in the above figures can be determined mathematically as

$$
\begin{aligned}
& V_{x o}=\sum_{n=1,3,5}^{\infty} \frac{2 V_{d c}}{n \pi} \sin (n \omega t) \\
& V_{x y}=\sum_{n=1,3,5}^{\infty} \frac{2 V_{d c}}{n \pi}[\sin (n \omega t)-\sin n(\omega t-\varphi) \\
& V_{x y, 1}=\frac{4 V_{d c}}{\pi} \cos \left(\omega t-\frac{\varphi}{2}\right) \sin \frac{\varphi}{2} \\
& V_{x y, r m s}=0.9 V_{d c} \sin \frac{\varphi}{2}
\end{aligned}
$$

As the PWM greatness differs, it brings about the difference in yield voltage.

In a full-connect inverter, IGBT's are utilized as switches that have appropriate qualities as required for the application. An IGBT is a unidirectional device, and it can just turn $\mathrm{ON}$ the forward way. For a singlephase inverter, it requires four signal contributions for each gate terminal of IGBT. Two signals at HIGH and the other to its complementary state.

\section{ISOLATION CIRCUIT}

The isolation circuit is one that assigns Pulse Width Modulation signals to inverter switches accordingly. A primary objective of an isolation circuit is to amplify the PWM signals and to isolate the DSP microcontroller from the inverter when the signal voltage exceeds. Fig. 5 shows a functional pattern of a primary control circuit related to a dead-band and isolation circuits

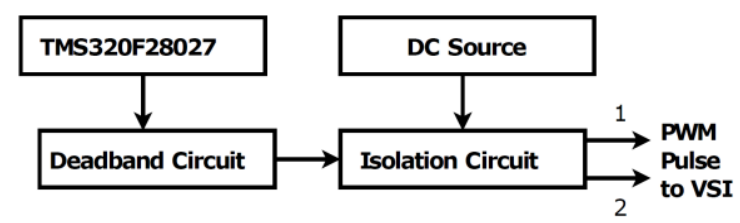

Fig.5. The Functional pattern of a controller circuit

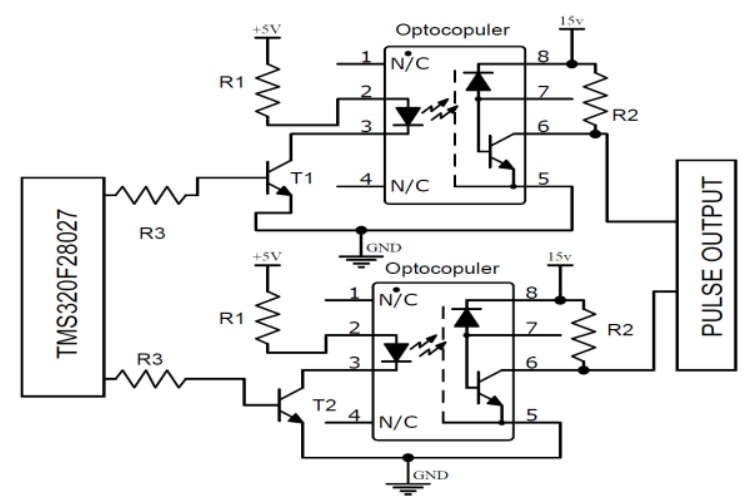

Fig.6. Schematic representation of an isolation circuit

\subsection{Sinusoidal pulse width modulation}

In the SPWM method, there are various quantities of output pulses per half cycle, and of the distinctive pulse width. The width of each pulse is fluctuating with respect to the plentifulness of a sine wave assessed at the Focal point of a similar pulse.

The rms ac output voltage

$v_{o}=v_{s} \sqrt{\frac{p \delta}{\pi}} \rightarrow v_{s} \sqrt{\sum_{m=1}^{2 p} \frac{\delta_{m}}{\pi}}$

Where $\mathrm{P}=$ Total pulses and $\delta=$ Pulse Width

\subsection{Dead-band circuit}

TMS320F28027 can create the PWM signals in the wide range from a couple of $1 \mathrm{~Hz}$ to $100 \mathrm{kHz}$. In any case, because of a tremendous scope of PWM signals, now and again, the force switches may not recognize the required sign correctly, and this may prompt dormancy of the entire framework. To forestall such an issue, it is prescribed to gracefully a dead band for a brief period. Fig.7. Displays the G1 and G2 pulses got from a dead-band circuit. 


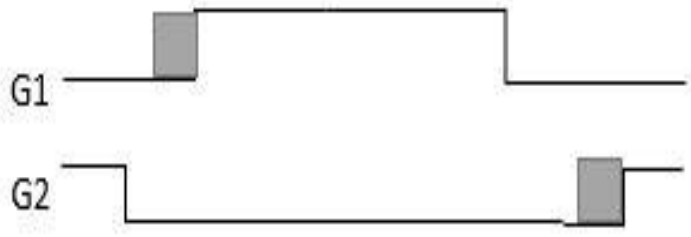

Fig.7.The Dead region from a dead-band circuit

The PWM signals with the dead area are created from the dead-band circuit appeared in Fig.8. The output signals from the dead band circuit are given to an isolation circuit in this manner; it went to the switches.

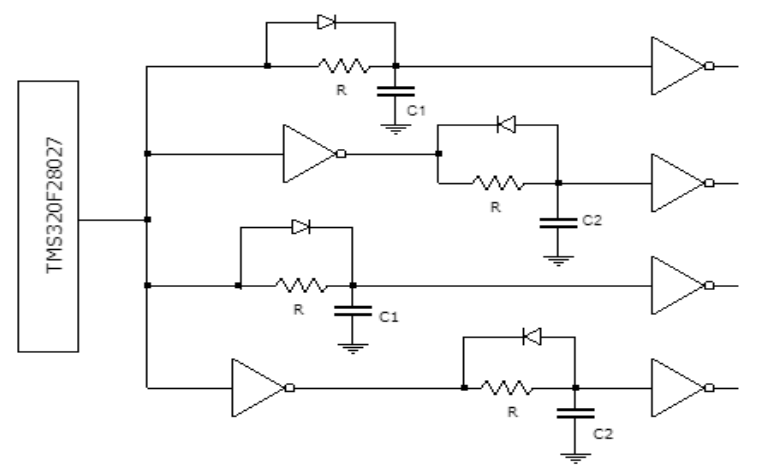

Fig.8. Schematic diagram of a dead-band circuit

The DSP TMS320F28027 launchpad is utilized for producing SPWM pulses. By thinking about the measures, the $50 \mathrm{~Hz}$ frequency is accomplished through a period time of 20 milliseconds $(f=1 / T)$, the signals are to be produced inside the predetermined $20 \mathrm{~ms}$, which are similarly appropriated into $10 \mathrm{~ms}$ HIGH and 10ms LOW. In the commonsense execution process, the applied program is formed and dumped into the DSP module utilizing CCS studio. At first, the output waveforms are found in a CRO to get exact and linear activating pulses, additionally limiting the errors.

The filter circuit is intended to decrease the harmonic levels at the output terminals before associating with burdens to secure a straight and unadulterated Sinusoidal Wave.

\section{LC Filter}

The L-filter accomplishes low attenuation of the inverter, a capacitor in parallel is expected to an extra lessening of the switching frequency. The frequency is determined from the condition given underneath

$$
f_{\mathrm{o}}=1 / 2 \pi \sqrt{ } L C
$$

The $\mathrm{L}$ decides the wave in the inductor current and lessens the low-frequency harmonics. The voltage over the inductor is:

$$
V_{L}=V_{I a}-V_{g a}
$$

where $\mathrm{V}_{\mathrm{Ia}}=$ Input Voltage and $\mathrm{V}_{\mathrm{ga}}=$ filter output

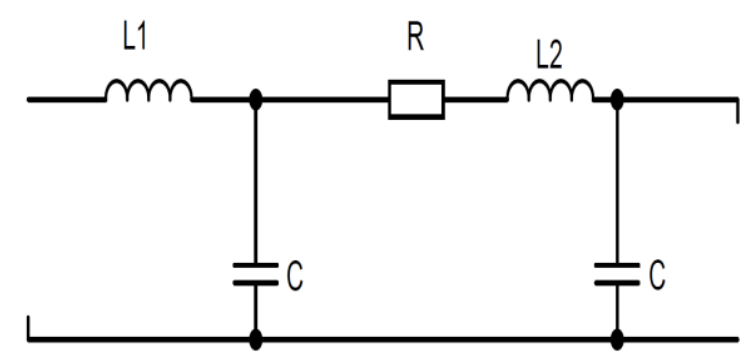

Fig.9. L-C filter topology

To calculate the inductor current, the values of VIa and $V g a$ are expressed in equations given

$$
\begin{aligned}
& V I a=2 / 3 V_{D C}, V_{g a}=1 / 2 V_{D C} \\
& V_{L}=2 / 3 V_{D C}-1 / 2 V_{D C}=1 / 6 V_{D C}
\end{aligned}
$$

Line-to-Neutral Voltage

$\mathrm{V}_{p}=\frac{V_{l}}{\sqrt{3}}=\frac{\sqrt{2} V_{s}}{3}=0.4714 V_{s}$

\section{HARDWARE AND RESULT ANALYSIS}

The expected equipment for the inverter is created, as appeared in Fig.10.schematic presentation. It is actualized in equipment with an isolation circuit, AC source, DC rectifier unit, IGBT module, TMS320F28027, Dead-band circuit, and an induction motor. The equipment arrangement is created, and results are confirmed by breaking down the qualities at various levels. A schematic appeared in fig. 10 clarifies the framework of the inverter activity. Fig.11. Shows the inverter's equipment arrangement with outside DC source, IGBT module with associated capacitor bank, rectifier unit, Isolation Circuit, TMS320F28027 microcontroller, heat discharge fan, and measurement hardware with protection circuit. The voltage source inverter input is associated with the rectifier unit from AC mains of $240 \mathrm{~V}$. The Voltage from the DSP Launchpad is of just $2 \mathrm{~V}$ appeared in fig.12(c). Be that as it may, as a prerequisite for the activating of IGBT's, the pulse required is $15 \mathrm{~V}$. The enhancement of the pulse adequacy is accomplished utilizing the amplifying or isolation circuit, which is planned to utilize Optocouplers and Transistors. An Isolation circuit is used to give protection between Driver Circuit and Power Circuit. The optocoupler is functioning as an isolating component in a circuit going about as an interface between the control circuit and the power circuit. The power circuit is given with more than $200 \mathrm{~V}$, and the conduction way can be hindered by separating the control or Isolation circuit. 


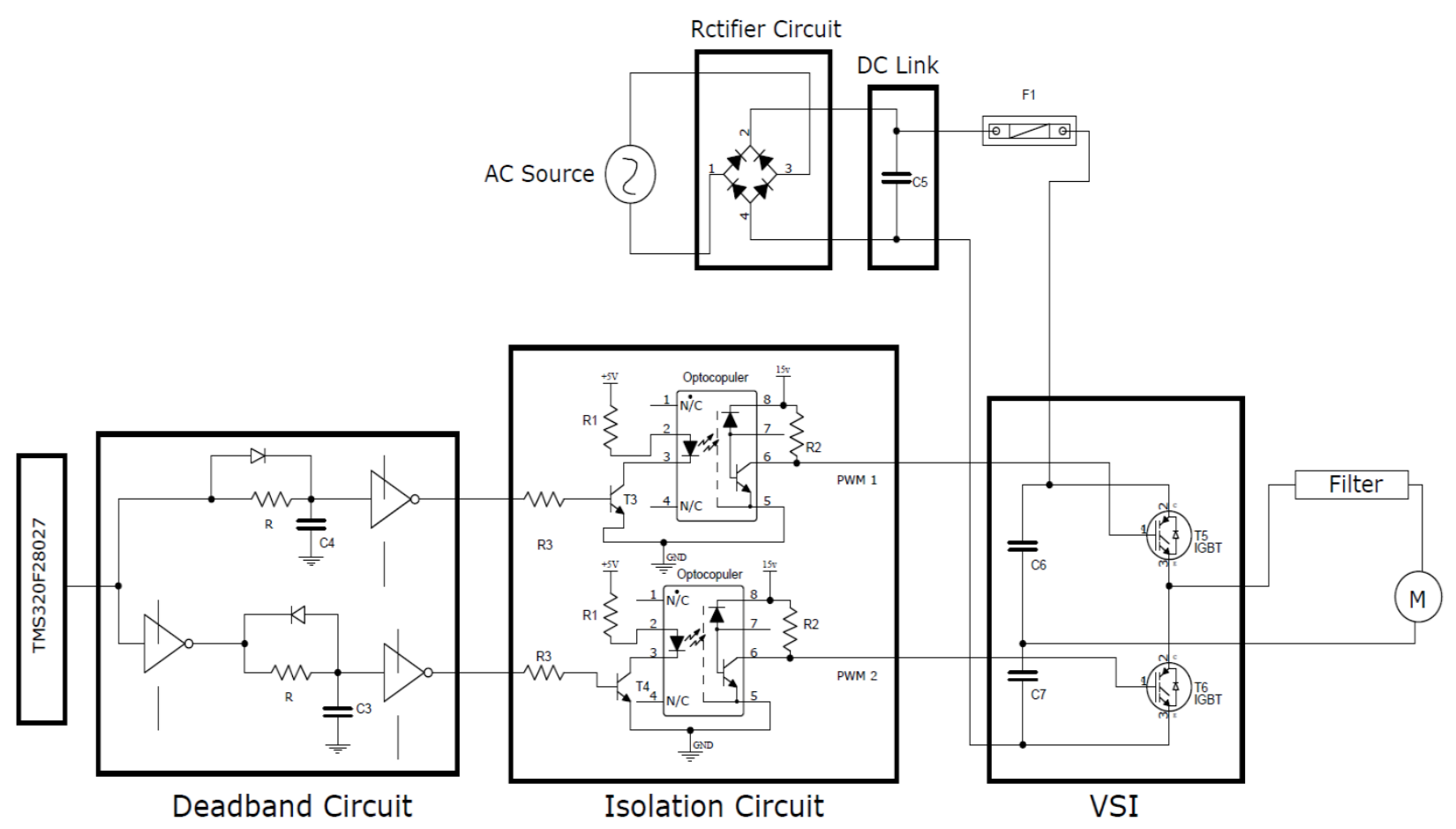

Fig.10.The schematic diagram for the inverter circuit

The IGBT switches module is associated with the Capacitor bank to keep up the steady voltage to be altered without interferences. The arrangement is outfitted with a thermistor, when overabundance heat produces while exchanging the cooling fan is naturally transformed on by switching the relays without hesitation by giving the thermistor signal.
At first, 12(a) demonstrates the non-inverting Pulses and its complementary pulses given to the switches S1S2 and S3S4 separately. Fig.12 (b) represents the PWM pulses with the dead band interference of $20 \mu \mathrm{s}$ I .e. $50 \mathrm{~Hz}$ exchanging recurrence. Fig 12 (c) shows the $2 \mathrm{v}$ output from TMS320F28027. Also, 12(d) shows the enhanced $15 \mathrm{v}$ yield from the isolation circuit.

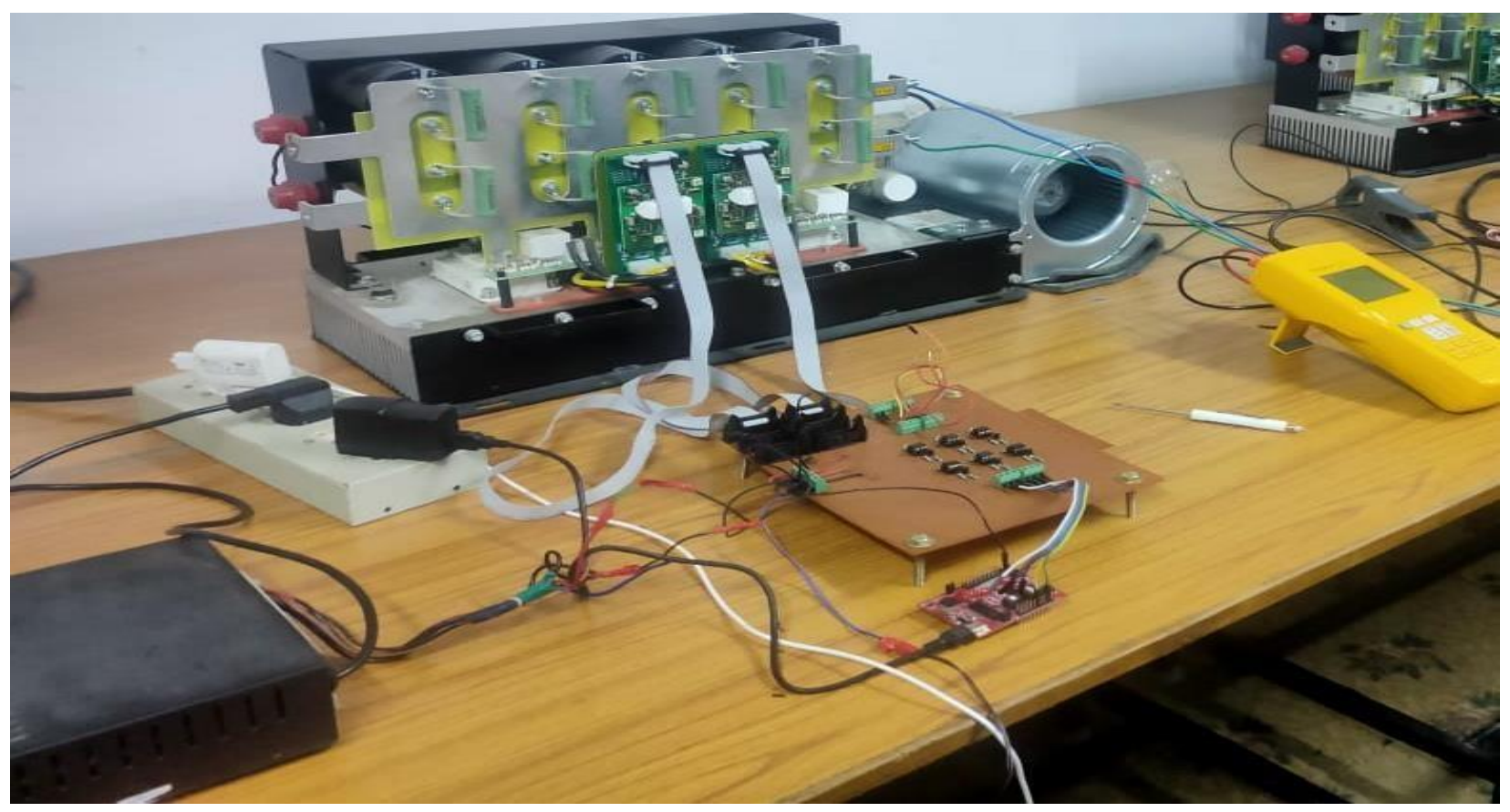

Fig.11. Hardware Implementation of Inverter 

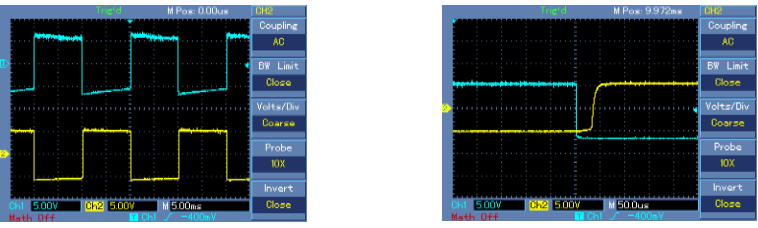

12(a)Pulse by microcontroller

12(b)Delay by Dead-band
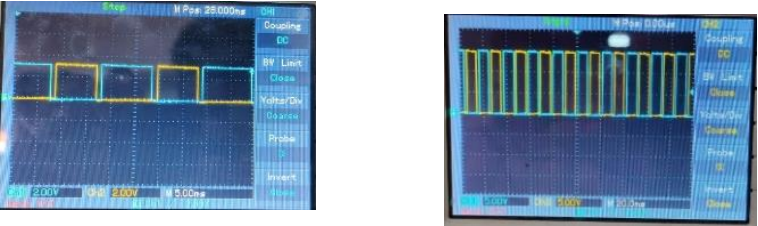

12(c) 2v pulse from MCU

The resultant output of an inverter is a commonly square wave. The exhibition of the inverter is trialed without filters, and an induction motor of appraisals $230 \mathrm{~V}$ and 1500 watts is utilized as a load to withstand the harmonics nearness and non-linear sinusoidal waveform brought about by a variety of PWM. Fig.13 shows the output voltage, frequency, and harmonics presence in output terminals.

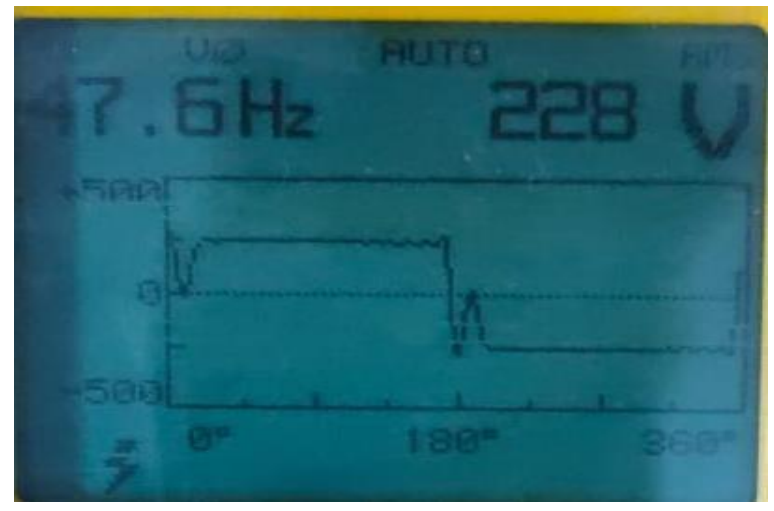

Fig.13.Hardware output voltage and frequency

The VSI with load execution examination appears in table.1.

\begin{tabular}{|c|c|c|c|}
\hline SI.No & $\begin{array}{c}\text { Amplitude } \\
\text { modulations }\end{array}$ & $\begin{array}{c}\text { Output Load } \\
\text { Voltages in } \\
\text { Volts }\end{array}$ & $\begin{array}{c}\text { Speed of } \\
\text { IM in rpm }\end{array}$ \\
\hline 1. & 1 & 237 & 1375 \\
\hline 2. & 0.8 & 228 & 1242 \\
\hline 3. & 0.6 & 214 & 1308 \\
\hline 4. & 0.4 & 209 & 1190 \\
\hline
\end{tabular}

Table.1.Output load voltages with different amplitude and modulations

The further investigation of changing over square wave voltage separated into sinusoidal wave voltage by receiving a low pass filter with the arrangement of inductance $\mathrm{L}$ and shunt capacitance $\mathrm{C}$ are finished utilizing the MATLAB Simulink programming, where the outcomes have appeared in fig. 14 .

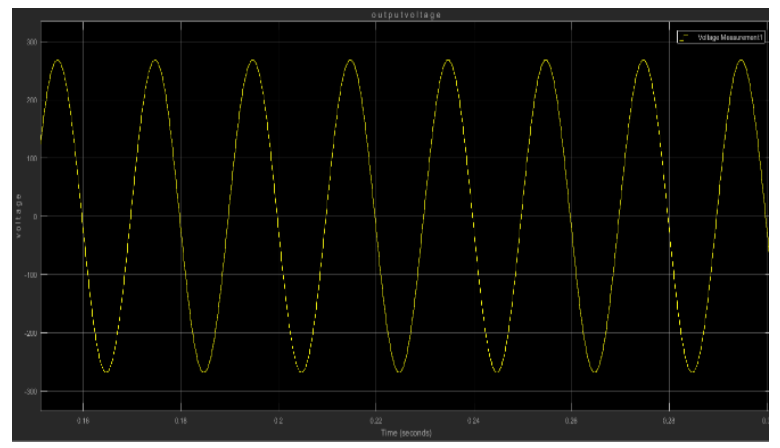

Fig.14. Simulation output of VSI with filter

\section{CONCLUSION}

The project Clarifies, single-phase voltage source inverter execution utilizing Digital Signal Processor TMS320F28027 Launchpad. The DSP controlled SPWM, took care of into the IGBT's, which creates the square type $\mathrm{AC}$ voltage waveform with various pulse widths in every half-cycle. The whole dead-band circuit can be dumped into DSP by giving the appropriate program. The voltage source inverter output can be sinusoidal with the shunt LC filter circuit used to regulate the voltage diminishing the Total Harmonic Distortion, which prompts smooth and reliable operation of the load. Along these lines, it tends to be summed up that TMS320F28027 DSP Launchpad is utilized proficiently for Voltage Source Inverters and flexible loads like Dynamic Voltage Restorer, Induction Heating and Controllable Loads.

Authors would like to offer their thanks towards the management of Gokaraju Rangaraju Institute of Engineering and Technology.

\section{References}

1. T. Noguchi, H. Tomiki, S. Kondo, I. Takahashi "Direct Power Control of PWM Converter without Power Source Voltage Sensors" IEEE Transaction on Industry Applications, Vol. 34, No.3, (May/June 1998), pp.473-479.

2. V. Blasko "Adaptive Filtering for Selective Elimination of Higher Harmonics from Line Currents of a voltage source converter" IEEE IAS Conference(1998), pp.1222-1228.

3. J.G. Neilson, M Newman, H Neilsen, and F. Blaabjerg, "Control and Testing of a Dynamic Voltage Restorer at medium voltage level, "IEEE transaction on Power Electronics Society, (November 2-6,2004),pp.749-754.

4. Praveen J, Bishnu P Muni, S Venkateshwarlu, and H.V Makthal Review of Dynamic Voltage Restorer for Power Quality Improvement, in Proc. Of $30^{\text {th }}$ Annual Conference of the IEEE Industrial Electronics Society,(November 26,2004), pp. 749-754.

5. Vinay Kumar AWAAR, Praveen Jugge and Tarakalayani S, "PQ Improvement By Moderation of Multi-Level Inverter Controlling 
Techniques and Intensifying the performance of DVR," in Advance in Electrical and Electronics Engineering, Vol. 13, No.2. (2015), pp.107-114.

6. Vinay Kumar. A, J Praveen, S Tarakalyani "Various Power Quality Issues: Measurement of Flicker and Mitigation of Voltage Sag, "ISSN0973-1334, Vol.10, N0.3, (September 2014), pp.44-55.

7. Vinay Kumar A, J Praveen "Power Quality Improvement by using Dynamic Voltage Restorer and Direct Power Control Strategy Methods" ISSN 2229-3027, Vol-1, Issue-2,(JanApril-2011), pp. 20-25.

8. N. H. Woodley, L. Morgan, and A. Sundaram. "Experience with an Inverter-based dynamic voltage restorer." IEEE trans. Power Delivery. Vol. 14, No.3, pp.1181-1186.(1999)

9. IEEE Standard 1159-2009: "Recommended Practice for Monitoring Electric Power Quality."

10. IEEE Standard 1250-2011 "Guide for Identifying and Improving Voltage Quality in Power Systems."

11. William E.Brumsickle, Robert S. Schneider, A.Luckjiff, Deepak M.Divan, and F. McGranaghan "Dynamic Sag Correctors: CostEffective Industrial Power line Conditioning" IEEE Tran. On Industrial Applications, Vol. 37, No.1( Jan/Feb 2001), pp 212-217.

12. Neil H. Woodley, P.E, Sr.Member "Field Experience with Dynamic Voltage Restorer (DVR) Systems," IEEE Power Engineering Society Winter Meeting (2000)-Singapore.

13. D.M. Vilathgamuwa, A.A.D.R.Peera, and S.S. Choi, "Voltage sag compensation with energyoptimized dynamic voltage restorer," IEEE Trans. Power Del., vol. 18, no. 3, pp. 928-936, (Jul. 2003).

14. Bankupalli, P.T., Srikanth Babu, V., Suresh Kumar. T, International Journal of Applied Engineering Research, 10(16), 2015, pp. 37057 37062.

15. Y. W. Li, F. Blaabjerg, D. M. Vilathgamuwa, and P. C. Loh, "Design and comparison of highperformance stationary-frame controllers for DVR implementation," IEEE Trans. Power Electron, vol. 22, no. 2, pp. 602-612, (Mar. 2007).

16. Steven R. Aschraft and S. Mark Halpin, "DC-AC Inverters for Static Condenser and Dynamic Voltage Restorer Applications," IEEE Online Proceedings, (1996), pp. 215-219.

17. A. Ghosh and G. Ledwich, "Compensation of distribution system voltage using DVR," IEEE Trans. Power Del., vol. 17, no. 4, pp. 1030-1036, (Oct. 2002).

18. Vinay Kumar AWAAR, Praveen JUGGE, Tarakalyani S, "PQ Improvement by moderation of multi-level inverter controlling techniques and intensifying the performance of DVR," AEEE Trans. Power Engineering And Electrical Engineering, vol.13, no.2, pp.107-114, (June
2015). DOI: 10.15598/aeee.v13i2.1244.

19. J.-Y. Lee, "Single-stage AC/DC converter with input-current dead-zone control for wide input voltage ranges," IEEE Trans. Ind. Electron., vol. 54, no. 2, pp. 724-732, (Apr. 2007).

20. N. Golbon and G. Moschopoulos, "A low-power ac-dc singlestage converter with reduced dc bus voltage variation, "IEEE Trans. Power Electron, vol. 27, no. 8, pp. 3714-3724, (Jan. 2012).

21. Moon Ho Kang, Yoon Chang Park, "A real-time control platform for rapid prototyping of induction motor vector control," SpringerVerlag, Electrical Engineering (2006) 88: 473483. 